40th AIAA/ASME/SAE/ASEE Joint Propulsion Conference and Exhibit, July 11-14, 2004, Fort Lauderdale, FL

\title{
Detonation Initiation via Imploding Shock Waves
}

\author{
S.I. Jackson* and J.E. Shepherd ${ }^{\dagger}$ \\ California Institute of Technology, Pasadena, CA, 91125, USA
}

\begin{abstract}
An imploding annular shock wave driven by a jet of air was used to initiate detonations inside a $76 \mathrm{~mm}$ diameter tube. The tube was filled with a test gas composed of either stoichiometric ethylene-oxygen or propane-oxygen diluted with nitrogen. The strength of the imploding shock wave and the sensitivity of the test gas were varied in an effort to find the minimum shock strength required for detonation of each test mixture. The results show that the minimum required shock strength increases with mixture sensitivity and suggest that impractically large shock driver pressures are required to initiate detonations in ethylene-air or propane-air mixtures when using this technique.
\end{abstract}

\section{Nomenclature}

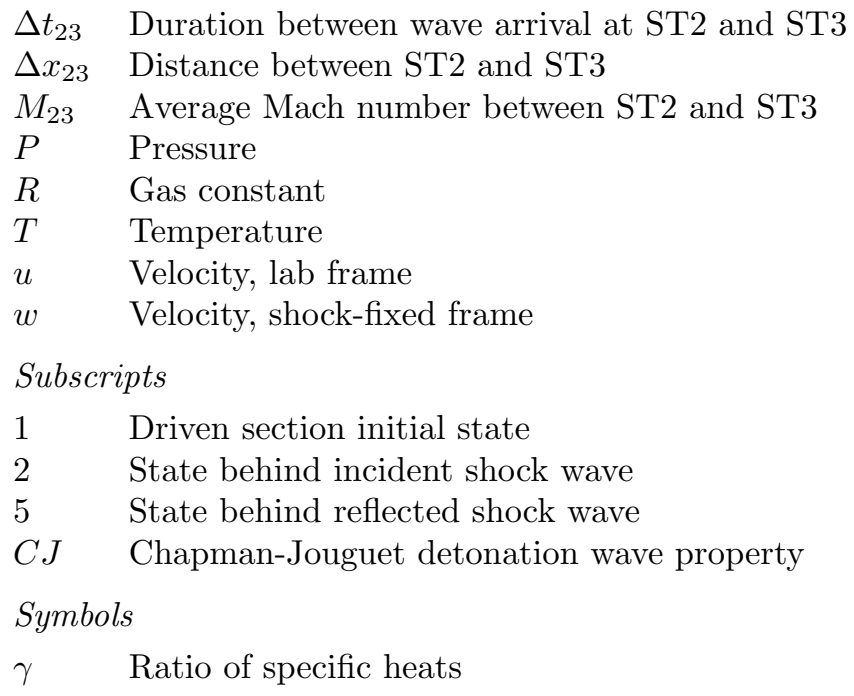

\section{Introduction}

TMLODING shock waves have intrigued researchers for decades due to their inherent ability to become increasingly overdriven. Gas processed by a shock wave is adiabatically compressed and accelerated in the direction of shock propagation. Imploding shock geometries force the shocked gas into an ever-decreasing area that creates additional compression as compared to that of planar geometries. The end result is a

\footnotetext{
*Graduate student, Aeronautics, 1200 E. California Boulevard, MC 205-45, Pasadena, CA, 91125.

${ }^{\dagger}$ Professor, Aeronautics, 1200 E. California Boulevard, MC 105-50, Pasadena, CA, 91125.

Copyright (c) 2004 by California Institute of Technology. Published by the American Institute of Aeronautics and Astronautics, Inc. with permission.
} 
positive feedback cycle: The increased compression accelerates the shock, which, in turn, acts to further increase the post-shock pressure. This cycle continues throughout the implosion process and can result in extremely high post-shock pressures and temperatures as the wave radius approaches zero.

The imploding shock solution was first solved analytically for cylindrical and spherical geometries in 1942 by Guderley, ${ }^{1}$ who assumed that the trajectory of the imploding shock followed a power law. The presence of a high-pressure and high-temperature focal region in the implosion was demonstrated experimentally by Perry and Kantrowitz, ${ }^{2}$ who used a shock tube with a teardrop-shaped obstruction inserted into the end of a shock tube to shape a planar shock wave into a cylindrically imploding wave. While they did not obtain pressure measurements, they were able to image ${ }^{2}$ luminosity emitted from ionized argon at the focus of the imploding shock indicating the presence of high-temperature gas. Subsequent work further developed theoretical methods ${ }^{3,4,5,6,7,8,9}$ and experiments ${ }^{10,11,12,13,14,15,16,17,18,19,20,21,22}$ to better understand the shock implosion process.

The current interest in air-breathing pulse detonation engines (PDEs) has led researchers to search for efficient methods of initiating insensitive hydrocarbon-air mixtures such as such JP10-air or $\mathrm{C}_{3} \mathrm{H}_{8}$-air. The ideal technique for detonation initiation in fuel-air mixtures would require a small amount of electrical energy, on the order of milliJoules, and no sensitizer fuel. This technology has yet to be realized and, as a result, current PDEs use initiator tubes sensitized with oxygen ${ }^{23}$ or detonate more sensitive mixtures such as $\mathrm{H}_{2}$-air. ${ }^{24,25}$

Efforts to maximize the efficiency of initiator tubes have focused detonation waves into insensitive mixtures to create high-enthalpy focal regions that evolve into self-sustaining detonation waves. ${ }^{20}$ Jackson and Shepherd ${ }^{26}$ have successfully detonated $\mathrm{C}_{3} \mathrm{H}_{8}$-air mixtures in a detonation tube using an initiator ${ }^{27,28}$ that generates and focuses toroidally imploding detonation waves. Numerical simulations by $\mathrm{Yu}$, Wang, and $\mathrm{He}^{29}$ indicate that the interaction between the reflected main shock and the contact surface, which separates the gas driving the imploding wave from the gas to be detonated, creates a second imploding shock. This second implosion further increases the temperature and pressure near the wave focus above that predicted by a single imploding wave and greatly facilitates detonation initiation.

More recently, Li and Kailasanath ${ }^{30,31}$ have proposed using imploding shock waves, instead of detonation waves, to initiate insensitive mixtures. In particular, numerical simulations ${ }^{31}$ found that detonations could be initiated in a $14 \mathrm{~cm}$ (5.5 in) diameter tube filled with stoichiometric ethylene-air using an imploding shock wave created from the injection of a converging annular jet of fuel or air from the outer diameter of the tube. At the injection point, the jet had a Mach number of unity, a pressure of 2.0 bar, and a temperature of 250 K. For gas with a specific heat ratio $\gamma$ of 1.4, a jet with the aforementioned properties could be generated from a reservoir with a total pressure of 3.8 bar and a total temperature of $470 \mathrm{~K}$.

The concept of detonation initiation via a converging air jet is extremely appealing to designers of PDEs since it would eliminate the need for a spark plug and associated power supply or any sensitizer fuel. Furthermore, an engine in flight would have an abundant supply of high-pressure and high-temperature air available to create the imploding wave.

The current study used imploding annular shock waves driven by air jets to initiate detonations in a 7.6 $\mathrm{cm}$ (3.0 in) diameter tube filled with a test gas of either stoichiometric ethylene-oxygen or propane-oxygen diluted with varying amounts of nitrogen. The strength of the imploding shock wave and the sensitivity of the test gas were varied in an effort to find the minimum shock strength required for detonation of each mixture. The total pressure of the air jet that was used to create the implosion ranged from 3.2 bar to 16.8 bar and the total temperature ranged from $420 \mathrm{~K}$ to $790 \mathrm{~K}$. Thus, the jet properties were comparable to those of Li and Kailasanath. ${ }^{31}$

\section{Experimental Facility}

The experimental facility was a shock tunnel and consisted of a test section tube with an annular orifice which protruded into the end of a shock tube. The shock tube was used to generate imploding shock waves in the test section tube. A description of each component of the shock tunnel is included below. The operation 
of the facility is also discussed.

\section{A. GALCIT 6 Inch Shock Tube}

The GALCIT 6 Inch Shock Tube ${ }^{32}$ was used to create the primary shock wave in the experiment. The shock tube consists of a driver section with a $16.5 \mathrm{~cm}$ (6.50 in) inner diameter and a driven section with a $15.2 \mathrm{~cm}$

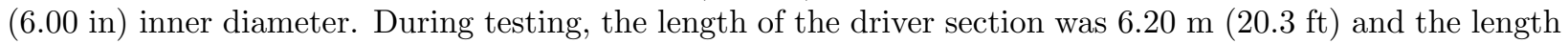
of the driven section was $11.3 \mathrm{~m}(37.0 \mathrm{ft})$. The end flange of the driven section contained a $10.8 \mathrm{~cm}(4.25$ in) diameter hole through which the front of the test section was inserted into the rear of the driven section. When assembled, the test section protruded $8.43 \mathrm{~cm}(3.32 \mathrm{in})$ into the shock tube.

The two sections were separated by a hydraulic clamp which was designed to hold the diaphragm in place during the experiment preparation. Typically, the clamp was pressurized to 172 bar (2500 psi) during the experiment. The driver section was then pressurized with gas while the driven section pressure remained constant at atmospheric pressure. This pressure difference caused the diaphragm to bulge into the driven section and contact a cruiciform blade cutting device (similar to those described elsewhere ${ }^{33,34}$ ) that was located immediately downstream of the diaphragm clamp. This cutter ruptured the diaphragm and caused it to petal open. The diaphragm will burst without use of the cutters but previous experience ${ }^{32,33}$ has shown that use of the cutters results in a more repeatable rupture pressure and reduces the chance of the diaphragm fragmenting and traveling downstream. The burst pressure is dependent on the diaphragm properties (material and thickness) as well as the shape of the cutter. Two differently shaped cutting devices available for the shock tube were able to rupture diaphragms at approximately $50 \%$ (cutter 1) and $80 \%$ (cutter 2) of their free burst pressure. Thus, three burst pressures were available for each diaphragm thickness by using cutter 1 , cutter 2 , or no cutter at all.

The driven section was equipped with four PCB 113A series piezoelectric pressure transducers which were flush mounted into the tube wall. Transducers ST1, ST2, ST3, and ST4 were located respectively at $3.85 \mathrm{~m}, 0.70 \mathrm{~m}, 0.20 \mathrm{~m}$, and $0.10 \mathrm{~m}$ from the shock tube end flange. The passage of the shock wave past transducer ST1 triggered the data acquisition system. The two intermediate transducers, ST2 and ST3, were used to record the shock arrival times in order to calculate the shock velocity. The transducer closest to the end flange provided pressure measurements near the annular orifice on the test section. Transducer data were recorded by a National Instruments data acquisition card and processed by a Labview program.

\section{Diaphragm Selection for Shock Tube}

Several different diaphragms were used in the shock tube to vary the shock strength. Diaphragms were made of dead soft aluminum and two different alloys were used: Al 1100-0 and Al 2024-0. Each alloy and cutter combination yielded a different burst pressure. Burst pressure data for the 6 Inch Shock Tube are shown in Figure 1 for the two diaphragm materials used in the experiments.

\section{B. Test Section}

The test section consisted of a $1.0 \mathrm{~m}$ (40 in) long main tube attached to a shorter $0.25 \mathrm{~m}$ (10.0 in) long extension tube with an annular orifice (Figure 2). Both components had a constant inner diameter of 76 $\mathrm{mm}(3.0 \mathrm{in})$. The two sections combined to form a tube with an internal length of $1.25 \mathrm{~m}$ (49.4 in).

During the experiment, the extension tube was inserted $8.43 \mathrm{~cm}$ (3.32 in) into the driven section of the shock tube and fixed in place using four latch clamps. The start of an annular orifice was located $4.62 \mathrm{~cm}$ (1.82 in) behind the start of the test section. The orifice was $2.54 \mathrm{~cm}$ (1.00 in) wide and interrupted by four $1.0 \mathrm{~cm}(0.4 \mathrm{in})$ wide support struts. The region of the test section that protruded into the shock tube had a $10.2 \mathrm{~cm}$ (4.0 in) outer diameter. Further dimensional information for this section is shown in Figure 3.

3 of 11

American Institute of Aeronautics and Astronautics Paper 2004-3919 


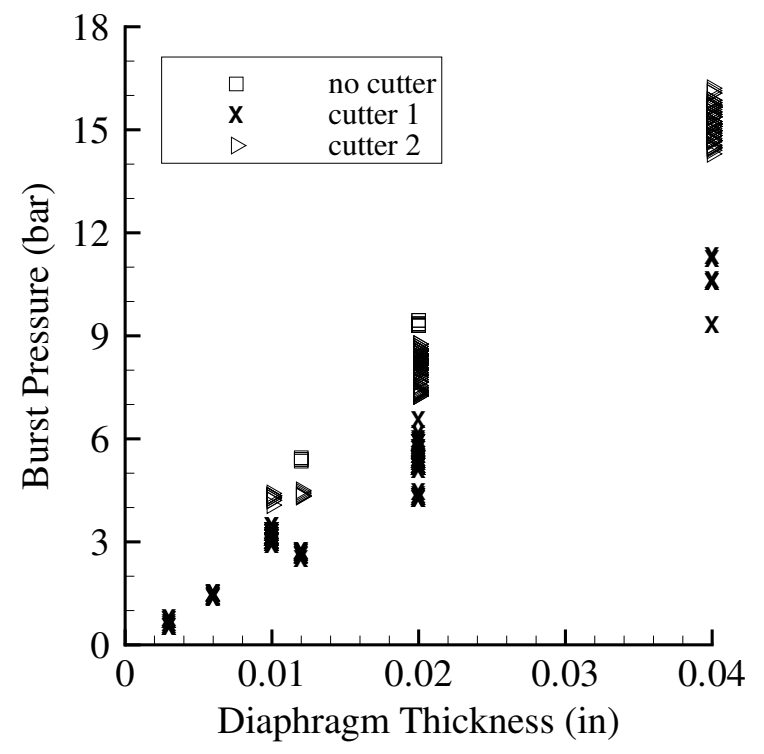

(a) Alloy Al 1100-0.

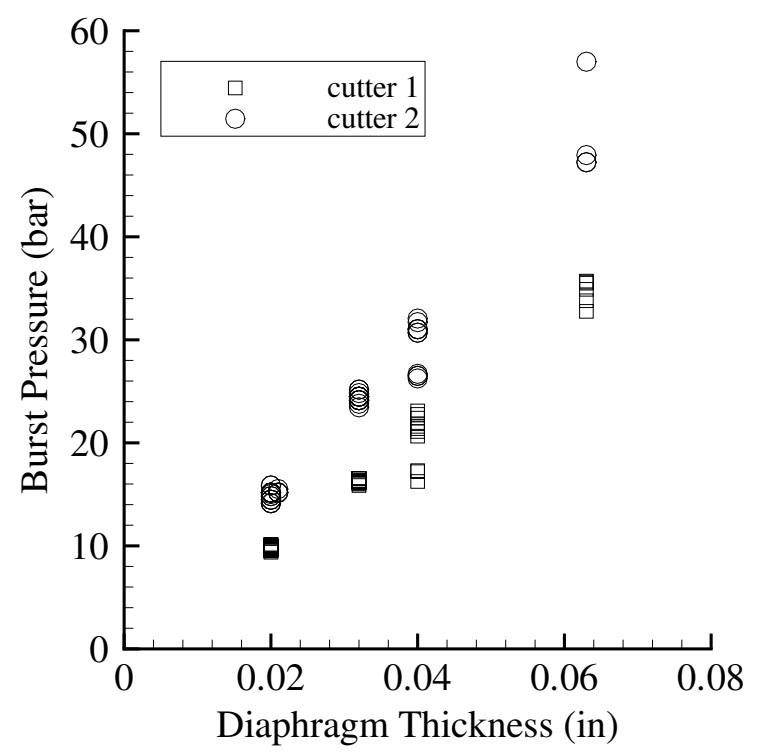

(b) Alloy Al 2024-0.

Figure 1. Burst data from the 6 inch shock tube for diaphragm alloys used in the experiments. Burst pressure is defined as the pressure difference between the driver and driven section at the moment of diaphragm rupture.

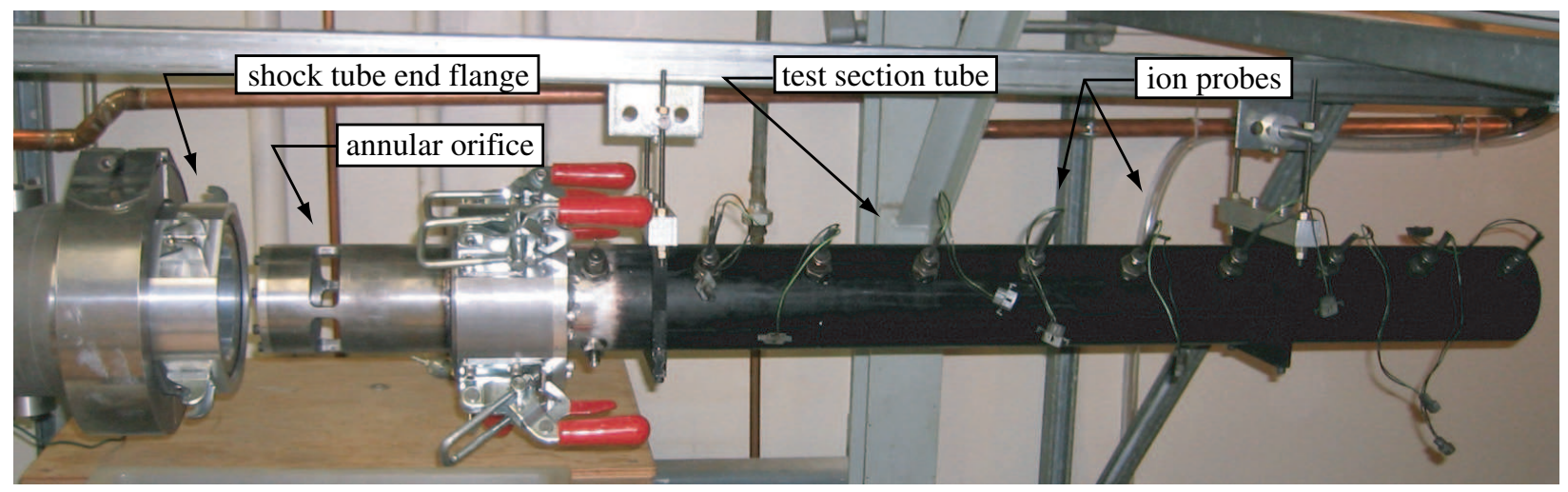

Figure 2. The test section is shown on the right. The end flange of the shock tube can be seen in the left side of the picture. The longer main tube is anodized black. The shorter extension containing the annular orifice and latch clamps is attached to the left side of the main tube.

The test section was equipped with four pressure transducers and nine ion probes. The ion probes were spaced equidistantly $10.4 \mathrm{~cm}$ (4.10 in) apart. The first ion probe was located $38.4 \mathrm{~cm}$ (15.1 in) from the inner face of the front test section flange. Ion probes were numbered I1 through I9 with the probe number increasing with increasing distance from the front test section flange. The pressure transducers TS1, TS2, TS3, and TS4 were located respectively at $27.9 \mathrm{~cm}(11.0 \mathrm{in}), 69.6 \mathrm{~cm}(27.4 \mathrm{in}), 1.21 \mathrm{~m}(47.9 \mathrm{in})$, and $1.25 \mathrm{~m}$ (49.4 in) from the inner face of the front test section flange. Transducer and ion probe data were recorded on two National Instruments data acquisition cards running in master-slave configuration and processed with a Labview program. Recording of the test section data acquisition system was triggered by the arrival of the 
incident shock wave at the rearmost transducer ST4 in the shock tube. The data acquisition system for the test section recorded $20 \mathrm{~ms}$ of data.

\section{Diaphragm Selection for Test Section}

The annular orifice in the test section was originally intended to be sealed by a thin layer of Mylar or aluminum tape during gas evacuation and filling of the test section. This tape was then to be ruptured by the high-pressure gas behind the shock wave. However, testing determined that tape thick enough to reliably seal the annular orifice did not rupture promptly upon arrival of the incident shock wave. To make matters worse, all quadrants of the annular orifice did not rupture simultaneously! The delay between the first and last quadrant to rupture ranged from $40 \mu$ s to $1 \mathrm{~ms}$ for diaphragms strong enough to maintain their integrity during the filling procedure.

To solve this problem, a short length of tube with two o-ring seals was inserted into the test section. This sliding gate was used to seal the annular orifice during test section evacuation and filling procedures but was moved to completely uncover the annular orifice before rupture of the shock tube diaphragm. Actuation of the slider gate was enabled by a wire connecting the slider gate to a rotatable

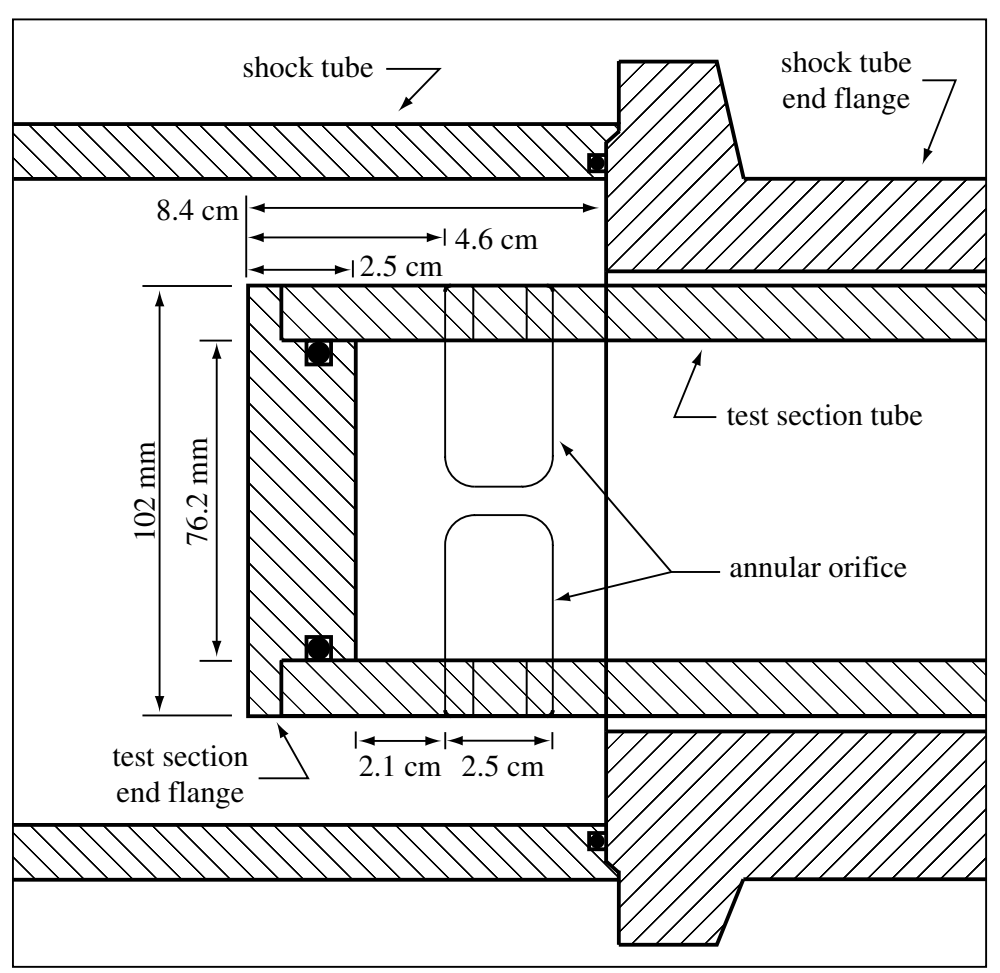

Figure 3. A sketch illustrating relevant dimensions of the test section while mated with the end flange of the shock tube. pull rod. Turning the rod pulled the slid-

ing gate along the tube axis. The sliding gate was $8.26 \mathrm{~cm}(3.25 \mathrm{in})$ long with an inner diameter of $6.35 \mathrm{~cm}$ (2.50 in). It is shown in Figure 4.

Use of the sliding gate to seal the annular orifice during gas evacuation and filling procedures allowed a much thinner diaphragm to be used to simply contain the test section gas during pressurization of the shock tube driver section. Aluminum foil with a thickness of $17.8 \mu \mathrm{m}(0.7$ mils $)$ was used as the test section diaphragm for all data shown.

\section{Basic Operation}

During an experiment, the test section slider gate was moved to seal the test section. Diaphragms were placed in the shock tube hydraulic clamp and on the annular orifice of the test section. The test section was then secured to the end of the shock tube using the latch clamps. The test section was evacuated and then filled to 1 bar with the premixed combustible test mixture. Test section gases were premixed for at least 15 minutes with a brushless fan suspended inside of the 9.25 liter mixture preparation vessel. Appropriate stochiometry was achieved by filling the mixture preparation vessel using the method of partial pressures.

Once the test section was filled, the slider gate was retracted leaving only the test section diaphragm to separate the test section gas from air in the driven section. Both sections of the shock tube were filled with 
air at atmospheric pressure. The driver section was then filled with air from a compressed air source until the shock tube diaphragm ruptured.

Rupture of the diaphragm resulted in a shock wave that traveled along the long axis of the shock tube to the end of the driven section. The shock reflected off the shock tube end flange and created a region of slow moving test gas with elevated pressure and temperature. The increased pressure behind the shock wave ruptured the secondary diaphragm that covered the annular orifice and created an imploding shock wave, followed by a converging jet of air, into the test section.

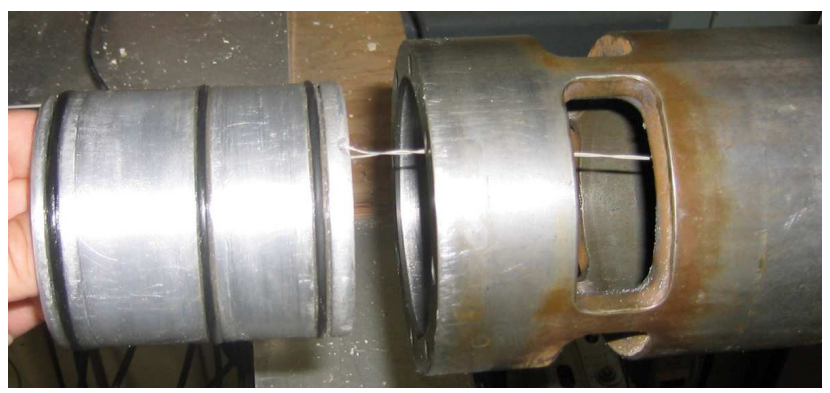

\section{Results and Analysis}

During each experiment, the Mach number of the

Figure 4. The sliding gate is shown removed from the test section. Note the wire connecting the sliding gate to the pull rod (not shown).

incident shock wave was determined from the wave arrival times at pressure transducers ST2 and ST3 in the shock tube.

$$
M_{23}=\frac{\Delta x_{23}}{\Delta t_{23} \sqrt{\gamma_{1} R_{1} T_{1}}}
$$

This allowed the post-shock conditions to be determined using the shock-jump equations for a perfect gas:

$$
\begin{aligned}
\frac{P_{2}}{P_{1}} & =1+\frac{2 \gamma}{\gamma+1}\left(M^{2}-1\right) \\
\frac{T_{2}}{T_{1}} & =1+\frac{2(\gamma-1)}{(\gamma+1)} \frac{\left(M^{2}-1\right)\left(1+\gamma M^{2}\right)}{M^{2}} \\
\frac{\Delta w}{a_{1}} & =-\frac{2}{\gamma} \frac{M^{2}-1}{M}
\end{aligned}
$$

where $\Delta w=w_{2}-w_{1}$ is the difference in flow velocity across the shock wave.

Using the properties of the incident shock and the boundary condition that the flow behind the reflected shock wave has zero velocity

$$
u_{5}=0,
$$

it is possible to determine the pressure ratio across the reflected shock as a function of the incident shock pressure ratio and Mach number.

$$
\begin{gathered}
\frac{P_{5}}{P_{2}}=\frac{(3 \gamma-1) \frac{P_{2}}{P_{1}}-(\gamma-1)}{(\gamma-1) \frac{P_{2}}{P_{1}}+(\gamma+1)} \\
\frac{P_{5}}{P_{1}}=1+2\left(\frac{P_{2}}{P_{1}}-1\right) \frac{1+\left(\frac{1}{2}+\frac{\gamma-1}{\gamma+1}\right)\left(M_{23}^{2}-1\right)}{1+\frac{\gamma-1}{\gamma+1}\left(M_{23}^{2}-1\right)}
\end{gathered}
$$

Thus, the pressure ratio across the reflected shock wave can be found as a function of the incident shock wave Mach number.

$$
6 \text { of } 11
$$




\section{A. Classification of data}

Each test was classified into one of four categories depending on the mode of combustion observed. The four categories were prompt detonation, deflagration-to-detonation transition (DDT), reflected detonation, and failed initiation. Examples of each category are shown in Figure 5 and descriptions are presented below. A wave was considered to be a detonation if the average wave speed in between each pair of ion probes or pressure transducers was within $10 \%$ of the Chapman-Jouguet velocity $U_{C J}$ and the shock wave was closely coupled to the combustion front.

\section{Prompt detonation}

The classification of prompt detonation indicates that the first pressure transducer and ion probe in the test section detected a detonation wave. An example of a prompt detonation is shown in Figure 5a. In the combined pressure-time and space-time diagram, the lower three pressure traces are from ST2, ST3, and ST4 in the shock tube and show propagation of the incident shock wave with a Mach number of 1.52. Shortly after a time of $9 \mathrm{~ms}$, the incident wave reflects from the shock tube end flange and generates an imploding wave in the test section. The imploding wave initiates a detonation in the test section. The shock wave associated with the detonation is recorded by the pressure transducers and the arrival of the reaction zone is detected by the ion probes. Ion probe data show that the detonation is propagating at a constant speed that is within $10 \%$ of $U_{C J}$. The coupling between the shock and the reaction front is evident in Figure $5 \mathrm{a}$. Meanwhile, in the shock tube, the reflected shock wave travels back down the tube and is chased by a larger pressure wave from the detonation initiation in the test section. The larger wave eventually overtakes the reflected shock as can be seen in the lowermost pressure trace.

\section{Deflagration-to-detonation transition}

An experiment was classified as DDT if the combustion mode was observed to transition from a deflagration to a detonation in the test section before the incident shock wave in the test section had reached the test section end flange. The DDT process can be observed in Figure 5b. A shock wave $(M=1.88)$ travels down the shock tube and reflects off the end flange as in the previous example. However, a detonation is not immediately initiated. The first wave recorded in the test section is a shock wave. The ion probes indicate that the shock is trailed by an accelerating deflagration. Near the middle of the test section $(7.0 \mathrm{dm})$ transition to an overdriven detonation $(P=7.0 \mathrm{MPa}, U=2670 \mathrm{~m} / \mathrm{s})$ occurs. The overdriven detonation relaxes as it travels down the test section and has a pressure and wave velocity characteriztic of a ChapmanJouguet detonation wave shortly before it reflects off the test section end wall.

\section{Detonation after reflection}

At times, the test section mixture did not react behind the test section incident shock wave. Instead, combustion initiated behind the reflected wave. In Figure 5c, a Mach 1.46 shock wave in the shock tube generated an implosion in the test section but failed to detonate the mixture. The implosion process propagated a shock wave through the test section which reflected from the test section end flange. A large explosion occurred near ion probe I8 roughly $2 \mathrm{~ms}$ after the reflected wave had passed by. The closest pressure trace, TS4, measured the explosion pressure to be $26 \mathrm{MPa}$ or more than eight times $P_{C J}$ for the test mixture. A significant ionization front was detected on only four of the nine transducers in the test section because the increased density behind the incident shock $(M=1.53)$ compressed the combustible test mixture into the last half of the tube.

\section{Failed initiation}

In some cases, low wave speeds and pressures were measured by the pressure transducers and no ionization was detected. Such experiments were labeled failed initiation attempts. Data from a failed initiation attempt

7 of 11

American Institute of Aeronautics and Astronautics Paper 2004-3919 


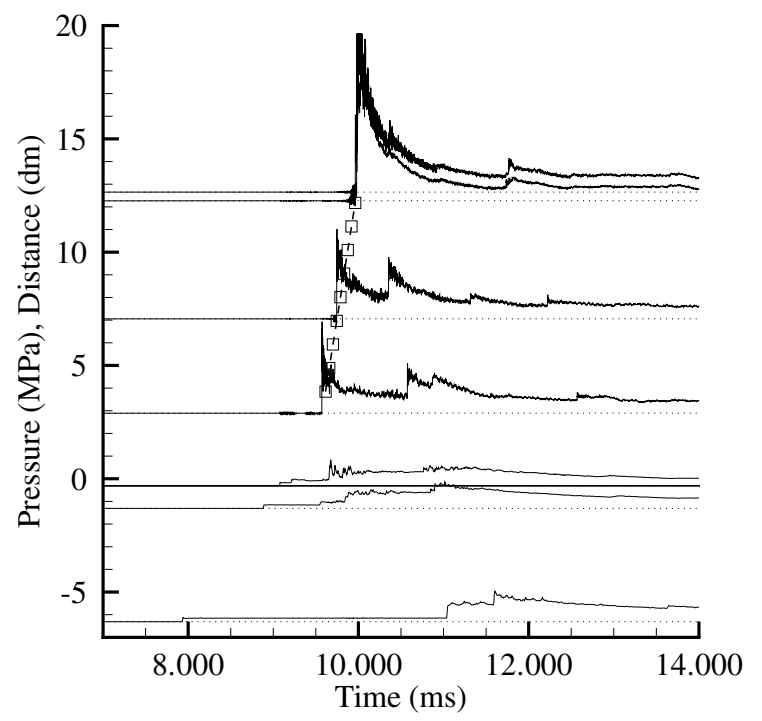

(a) Prompt detonation initiation in $\mathrm{C}_{2} \mathrm{H}_{4}+3 \mathrm{O}_{2}$ with $P_{5}$ $=5.7$ bar.

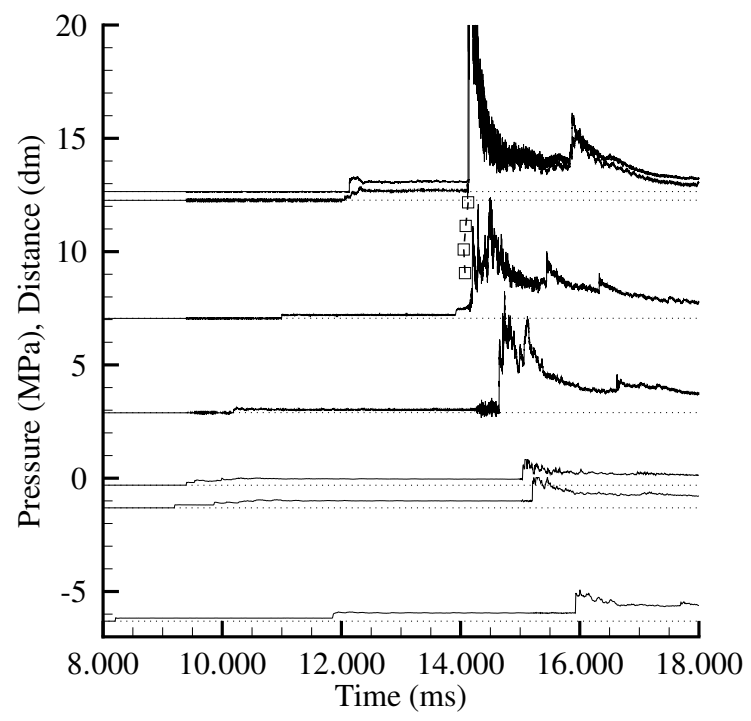

(c) Initiation behind reflected wave in $\mathrm{C}_{2} \mathrm{H}_{4}+3 \mathrm{O}_{2}+4 \mathrm{~N}_{2}$ $\left(50 \% \mathrm{~N}_{2}\right.$ by volume) with $P_{5}=4.9$ bar.

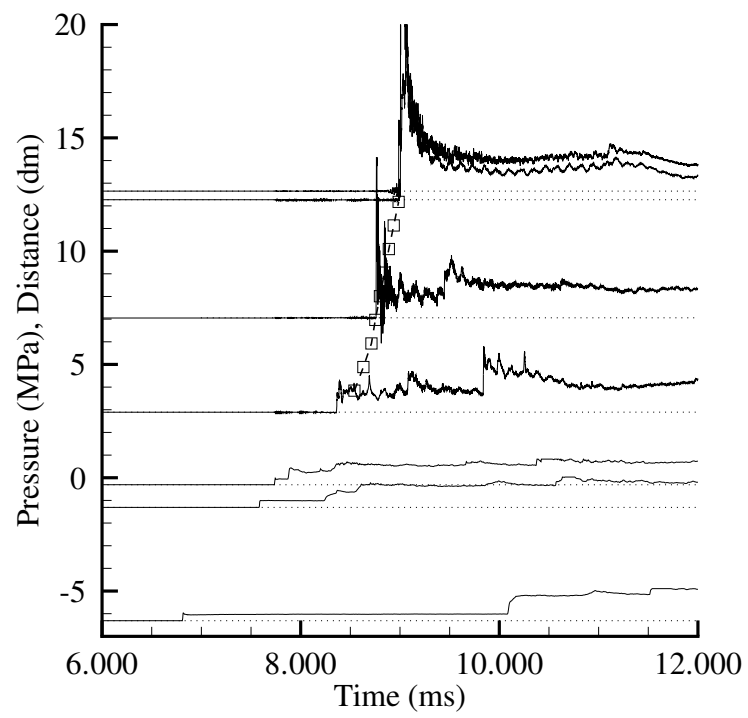

(b) DDT in $\mathrm{C}_{2} \mathrm{H}_{4}+3 \mathrm{O}_{2}+0.44 \mathrm{~N}_{2}\left(10 \% \mathrm{~N}_{2}\right.$ by volume) with $P_{5}=12.0$ bar.

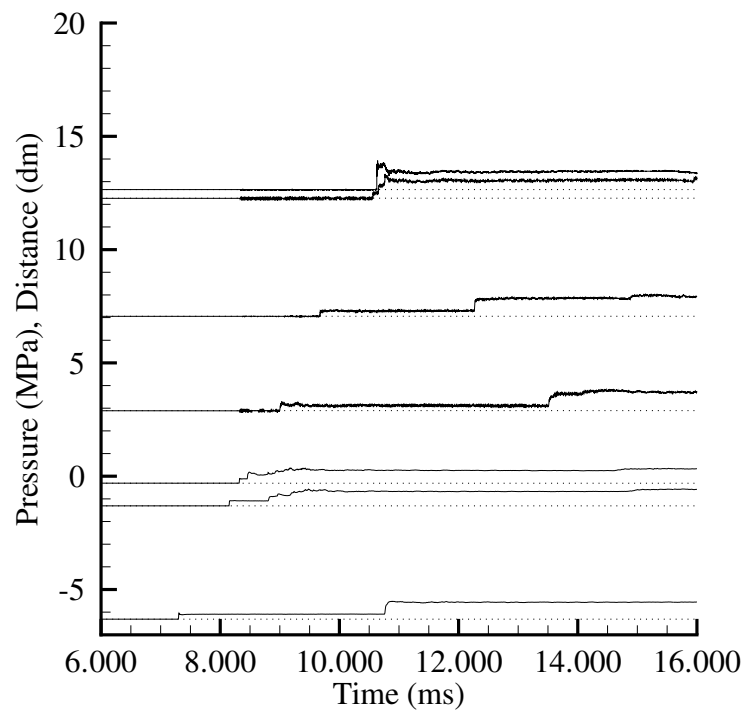

(d) Failed initiation attempt in $\mathrm{C}_{2} \mathrm{H}_{4}+3 \mathrm{O}_{2}+6 \mathrm{~N}_{2}(60 \%$ $\mathrm{N}_{2}$ by volume) with $P_{5}=8.5$ bar.

Figure 5. Four examples of experimental data are shown on combined pressure-time and space-time diagrams. Zero distance on the vertical axis corresponds to the inner edge of the test section front flange. Negative distances are located in the shock tube while positive distances are located in the test section. Pressure trace baselines (dotted line) indicate the location of the transducer relative to the zero distance. The square symbols connected by a dashed line are ion probe data indicating the location of a strong reaction front.

$$
8 \text { of } 11
$$


are shown in Figure 5d. A Mach 1.7 shock wave in the shock tube created a Mach 1.75 wave in the test section. The wave reflected from the test section end wall and traveled back into the shock tube with no combustion occurring in the $20 \mathrm{~ms}$ data acquisition window.

\section{B. Experimental Data}

The experimental results are shown in Figure 6 for stoichiometric ethylene-oxygen and propane-oxygen mixtures with varying nitrogen dilution. During the experiments, the reflected shock pressure $P_{5}$ was varied from 3.2 to 16.8 bar. The 16.8 bar value of $P_{5}$ was slightly above the maximum acceptable reflected shock pressure in the facility and, thus, was obtainable only once.

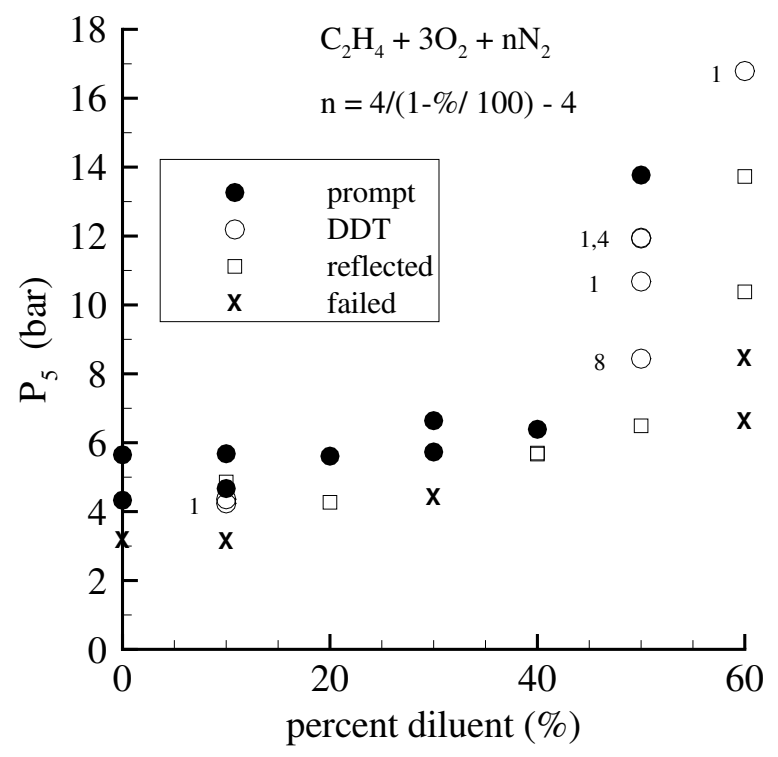

(a) Ethylene-oxygen-nitrogen data.

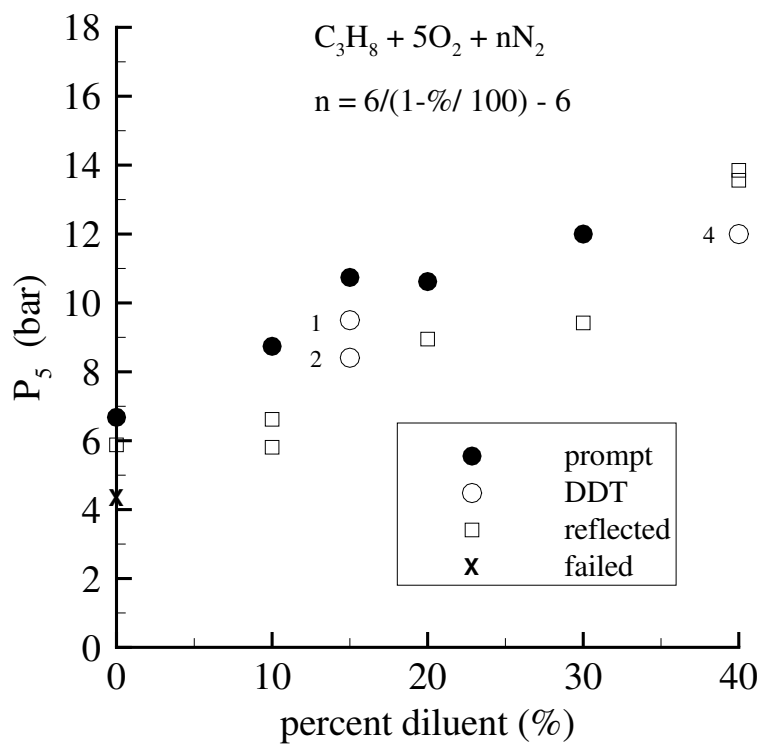

(b) Propane-oxygen-nitrogen data.

Figure 6. Initiation data for stoichiometric ethylene-oxygen and propane-oxygen test mixtures with varying nitrogen dilutions. $P_{5}$ is the reflected shock pressure in the shock tube. Numbers to the left of the DDT data symbols indicate the number of the ion probe that was closest to the DDT event.

The graphs in Figure 6 show that for a given diluent concentration, sufficiently high reflected shock pressure $P_{5}$ resulted in prompt detonation in the test section. As $P_{5}$ was decreased, prompt detonation no longer occurred, instead resulting in either DDT or detonation initiation behind the reflected shock. If $P_{5}$ was too low, combustion was no longer observed during the data acquisition window.

Both hydrocarbon mixtures required increasing $P_{5}$ to achieve detonation as the amount of dilution was increased. For the ethylene mixtures, this rate of increase jumped dramatically near dilution values of $50 \%$. Propane mixtures exhibited a steeper rate of increase for low dilution values and reached the maximum test point at $40 \%$ nitrogen dilution before the presence of a similar trend could be investigated.

The trend established by the data predicts that reflected shock pressures $P_{5}$ in excess of $P_{C J}=19$ bar would be required to achieve successful initiation in fuel-air dilutions ( $73 \%$ by volume for ethylene and $75 \%$ by volume for propane) even using the most optimistic extrapolation technique. 


\section{Summary and Conclusion}

Imploding annular shock waves were propagated into a detonation tube filled with ethylene-oxygennitrogen and propane-oxygen-nitrogen mixtures in an attempt to establish the minimum imploding shock strength necessary to successfully initiate detonations. Not surprisingly, the minimum shock strength required for initiation was found to increase with increasing dilution. The data indicate that initiating detonations in fuel-air mixtures would require shock driver pressures larger than the Chapman-Jouguet pressure for the fuel-air mixtures. It should be noted, however, that the experiments used a converging jet of air to create the imploding shock wave. Switching to a fuel-air driver gas could enhance the imploding shock initiation process by injecting a combustible mixture into the detonation tube rather than inert air. This could reduce the shock driver pressure required for initiation.

Increasing the diameter of the detonation tube to values used by Li and Kailasanath ${ }^{31}$ could also enhance the initiation process as it would allow the imploding shock wave to achieve higher values of compression during the implosion process. However, an increased tube diameter would also reduce the amount of confinement, moving potential reflecting surfaces away from the implosion focus, which has been shown to be detrimental to the success of the implosion process. ${ }^{26}$ Thus, it is not clear what net effect changing the diameter would have on the initiation process.

Future work will focus on determining where initiation occurs during the shock implosion process and investigate the effects of using fuel-air mixtures to drive the imploding shock wave. Experiments evaluating the effectiveness of using end wall reflectors to focus shock waves and initiate detonations in a similar diameter tube are also underway. These results will also be compared to those from initiation via imploding detonations ${ }^{26}$ to determine the merit of each technique.

\section{Acknowledgment}

The authors would like to thank P. Buraczewski for his design work as well as J. Haggerty, B. St. John, and A. Kiani for their patience and expertise during the construction process. We are also grateful to Dr. G. Roy at the Office of Naval Research and Dr. J. Blevins and Dr. C. Morris at NASA MSFC for their support and would like to acknowledge discussions on shock implosion with Dr. C. Li and Dr. K. Kailasanath.

This work was supported by the Office of Naval Research Grant Detonation Initiation by Annular Jets and Shock Waves (ONR grant number N00014-03-1-0931) and the National Aeronautics and Space Administration through the Graduate Student Researchers Program (Grant number NGT8-52937).

\section{References}

\footnotetext{
${ }^{1}$ Guderley, G., "Starke kugelige und zylindrische Verdichtungsstöße in der Nähe des Kugelmittelpunktes bzw. der Zylinderachse," Luftfahrtforschung, Vol. 19, No. 9, 1942, pp. 302-312.

${ }^{2}$ Perry, R. and Kantrowitz, A., "The Production and Stability of Converging Shock Waves," Journal of Applied Physics, Vol. 22, No. 7, July 1951, pp. 878-886. 1954.

${ }^{3}$ Butler, D., "Converging Spherical and Cylindrical Shocks," Tech. rep., Armament Research Establishment Report 54/54,

${ }^{4}$ Chisnell, R., "The normal motion of a shock wave through a non-uniform one dimensional medium," Proceedings of the Royal Society (London), Vol. A232, 1955, pp. 350.

${ }^{5}$ Meyer ter Vehn, J. and Schalk, C., "Self-similar Spherical Compression Waves in Gas Dynamics," Z. naturforsch, Vol. 37a, 1982, pp. 955-969.

${ }^{6}$ Devore, C. and Oran, E., "The Stability of Imploding Detonations in the Geometrical Shock Dynamics (CCW) Model," Physics of Fluids, Vol. A4, No. 4, 1992, pp. 835-844.

${ }^{7}$ Oran, E. and Devore, C., "The Stability of Imploding Detonations - Results of Numerical Simulations," Physics of Fluids, Vol. 6, No. 1, 1994, pp. 369-380.

${ }^{8}$ Jiang, Z. and Takayama, K., "Reflection and focusing of toroidal shock waves from coaxial annular shock tubes," Computers and Fluids, Vol. 27, No. 5-6, 1998, pp. 553-562. 375.

${ }^{9}$ Chisnell, R., "An analytic description of converging shock waves," Journal of Fluid Mechanics, Vol. 354, 1998, pp. 357-
}

10 of 11 
${ }^{10}$ Lee, J. and Lee, B., "Cylindrical Imploding Shock Waves," Physics of Fluids, Vol. 8, No. 12, 1965, pp. $2148-2152$.

${ }^{11}$ Setchell, R., Storm, E., and Sturtevant, B., "An investigation of shock strengthening in a conical convergent channel," Journal of Fluid Mechanics, Vol. 56, No. 3, 1972, pp. 505-522.

${ }^{12} \mathrm{Wu}$, J., Neemeh, R., and Ostrowski, P., "Experimental Studies of the Production of Converging Cylindrical Shock Waves," AIAA Journal, Vol. 18, No. 1, 1980, pp. 47-48.

${ }^{13}$ Matsuo, H. and Nakamura, U., "Cylindrically converging blast waves in air," Journal of Applied Physics, Vol. 52, No. 7, July 1981, pp. 4350-4507.

${ }^{14}$ Terao, K., "Experimental Study on Cylindrical and Spherical Implosions," Japanese Journal of Applied Physics, Vol. 22, No. 3, 1983, pp. 446-453.

${ }^{15}$ Matsuo, H., Ebihara, K., and Ohya, Y., "Spectroscopic study of cylindrically converging shock waves," Journal of Applied Physics, Vol. 58, No. 7, October 1985, pp. 2487-2491.

${ }^{16}$ Takayama, K., Kleine, H., and Gronig, H., "An Experimental Investigation of the Stability of Converging Cylindrical Shock Waves in Air," Experiments in Fluids, Vol. 5, No. 5, 1987, pp. 315-322.

${ }^{17}$ Terao, K. and Wagner, H., "Experimental study on spherical imploding detonation waves," Shock Waves, Vol. 1, 1991, pp. 27-34.

${ }^{18}$ Fujiwara, K., Hiroe, T., and Matsuo, H., "New method of generating cylindrical imploding shocks using a flyer disk," Applied Physics Letters, Vol. 61, No. 26, December 1992, pp. 3110-3112.

${ }^{19}$ Hosseini, S., Onodera, O., and Takayama, K., "Stability of Converging Cylindrical Shock Waves in a Vertical Annular Co-Axial Diaphragmless Shock Tube," Trans. Japan Soc. Aero. Space Sci., Vol. 42, No. 135, 1998, pp. 19-26.

${ }^{20}$ Murray, S., Thibault, P., Zhang, F., Bjerketvedt, D., Sulmistras, A., Thomas, G., Jenssen, A., and Moen, I., "The Role of Energy Distribution on the Transmission of Detonation," Proceedings of the International Colloquium on Control of Detonation Processes, Moscow, Russia, July 4-7, 2000.

${ }^{21}$ Hosseini, S., Onodera, O., and Takayama, K., "Characteristics of an annular vertical diaphragmless shock tube," Shock Waves, Vol. 10, 2000, pp. 151-158.

${ }^{22}$ Skews, B., Menon, N., Bredin, M., and Timofeev, E., "An experiment on imploding conical shock waves," Shock Waves, Vol. 11, 2002, pp. 323-326.

${ }^{23}$ Brophy, C., Sinibaldi, J., and Wittmers, N., "Initiation and Operation of Valveless PDE," Proceedings of the Seventeenth ONR Propulsion Meeting, edited by G. Roy and A. Ghoniem, Office of Naval Research, Arlington, VA 22217, June 2004, pp. $149-155$.

${ }^{24}$ Schauer, F., Stutrud, J., Bradley, R., and Katta, V., "AFRL/PRSC Pulse Detonation Engine Research Program," Proceedings of the 12th Annual Symposium on Propulsion, Propulsion Engineering Research Center, Ohio Aerospace Institute, Cleveland, OH, October 2002.

${ }^{25}$ Rasheed, A., Tangirala, V., Pinard, P., and Dean, A., "Experimental and Numerical Investigations of Ejectors for PDE Applications," 39th AIAA/ASME/SAE/ASEE Joint Propulsion Conference and Exhibit, July 20-23, 2003, Huntsville, Alabama AIAA 2003-4971.

${ }^{26}$ Jackson, S., Grunthaner, M., and Shepherd, J., "Wave Implosion as an Initiation Mechanism for Pulse Detonation Engines," 39th AIAA/ASME/SAE/ASEE Joint Propulsion Conference and Exhibit, July 20-23, 2003, Huntsville, Alabama AIAA 2003-4280.

${ }^{27}$ Jackson, S. and Shepherd, J., "Initiation Systems for Pulse Detonation Engines," 38th AIAA/ASME/SAE/ASEE Joint Propulsion Conference and Exhibit, July 7-10, 2002, Indianapolis, IN, AIAA 2002-3627.

${ }^{28}$ Grunthaner, M., Jackson, S., and Shepherd, J., "Design and Construction of an Annular Detonation Initiator," GALCIT Technical Report 2001.005, Graduate Aeronautical Laboratories, California Institute of Technology, Pasadena, CA 91125, 2001.

${ }^{29} \mathrm{Yu}, \mathrm{S} .-\mathrm{T}$. J., Wang, B., and He, H., "Direct Calculation of Wave Implosion for Detonation Initiation in Pulsed Detonation Engines," Proceedings of the Seventeenth ONR Propulsion Meeting, edited by G. Roy and A. Ghoniem, Office of Naval Research, Arlington, VA 22217, June 2004, pp. 169-180.

${ }^{30} \mathrm{Li}, \mathrm{C}$. and Kailasanath, K., "Detonation Initiation in Pulse Detonation Engines," 41st AIAA Aerospaces Sciences Meeting and Exhibit, January 6-9, 2003, Reno, NV, AIAA 2003-1170.

${ }^{31} \mathrm{Li}, \mathrm{C}$. and Kailasanath, K., "Detonation Initiation by Annular-Jet-Induced Imploding Shocks," Technical note submitted to the AIAA Journal of Propulsion and Power.

${ }^{32}$ Smith, J. and Coles, D., "A Description of the GALCIT 6" Shock Tube," Tech. Rep. FM-67-1, Graduate Aeronautical Laboratories, California Institute of Technology, June 1967.

${ }^{33}$ Roshko, A. and Baganoff, D., "A Novel Device for Bursting Shock-Tube Diaphragms," Physics of Fluids, Vol. 4, No. 11, 1961, pp. 1445-1446.

${ }^{34}$ Liepmann, H. W., Roshko, A., Coles, D., and Sturtevant, B., "A 17-Inch Diameter Shock Tube for Studies in Rarefied Gasdynamics," The Review of Scientific Instruments, Vol. 33, No. 6, 1962, pp. 625-631. 